\title{
Movements and Storages of Radiocesium in a Forest Ecosystem in Fukushima
}

\author{
Kyoto University, Nobuhito Ohte
}

The disaster that occurred at the Fukushima Daiichi Nuclear Power Plant in March 2011 resulted in a massive dispersion of radioactive cesium $\left({ }^{137} \mathrm{Cs}\right)$ over vast forests and other surrounding areas. The author has conducted intensive monitoring in a water catchment area located in northern Fukushima to determine and explain how exactly ${ }^{137} \mathrm{Cs}$ migrates to and builds up in a forest ecosystem before being discharged from it. This monitoring revealed that the amount of ${ }^{137} \mathrm{Cs}$ that is discharged from the forest over the course of one year was at least two orders of magnitude less than the estimated amount of deposition immediately after the disaster. It has been suggested that the migration takes place mainly in the form of suspended solids with particulate organics serving as important carriers. The largest ${ }^{137} \mathrm{Cs}$ pools in the forest ecosystem proved to be the litter layer and the topsoil. The circulation of ${ }^{137} \mathrm{Cs}$ was also indicated within flora, including tall trees. The dispersion of ${ }^{137} \mathrm{Cs}$ within the biological communities of animals and other creatures was more notable in terms of migration through food webs extending from animals that feed on fallen leaves and their fragments as compared to migration through food webs extending from animals that feed on live leaves. No increase in the ${ }^{137} \mathrm{Cs}$ concentration was observed with the rise in the trophic level, which demonstrates that no biological accumulation took place.

KEYWORDS: Fukushima, radioactive cesium, forest ecosystem, biogeochemical cycle, suspended solid, food web, biological accumulation, root absorption

\section{Introduction}

The accident that occurred at the Fukushima Daiichi Nuclear Power Plant in March 2011 resulted in a massive dispersion of radioiodine (approx. $1.5 \times 10^{17} \mathrm{~Bq}$ of ${ }^{131} \mathrm{I}$ ) and radioactive cesium (approx. $1.2 \times 10^{16} \mathrm{~Bq}$ of ${ }^{137} \mathrm{Cs}$ ) in Fukushima and its surrounding areas ${ }^{1)}$. The forest coverage exceeds 70 percent in most municipalities within these areas. The deposited radioactive materials raise concerns in terms of exposure in human habitats, damage to the forestry and forest product industries, and impairment of water sources in forests.

The initial survey, which was led by the Ministry of Education, Culture, Sports, Science

DOI : 10.15669/fukushimainsights.Vol.2.108

(C) 2021 Atomic Energy Society of Japan. All rights reserved.

Originally published in Journal of the Atomic Energy Society of Japan (ISSN 1882-2606), Vol. 58, No. 10, p. 589-593 (2016)

in Japanese. (Japanese version accepted: July 8, 2016) 
and Technology (MEXT) and the Ministry of Agriculture, Forestry and Fisheries (MAFF) soon after the deposition began in FY2011, indicated that the radioactive cesium that fell on forests was retained on the crowns of evergreen trees and in the litter layer around deciduous trees $^{1,2)}$. It has been indicated that clay minerals in soil strongly adsorb radioactive cesium ${ }^{3)}$. It has also been reported that radioactive cesium is discharged into streams and rivers along with soil particles due to any soil erosion and runoff (e.g., Wakiyama et al., 2010) ${ }^{4)}$.

In a forest ecosystem, the radioactive cesium deposited on tree crowns migrates toward the forest floor over time by means of eluviation caused by rain ${ }^{5)}$ or defoliation ${ }^{6,7)}$. Hashimoto et al. ${ }^{2)}$ conducted a numerical simulation based on data obtained up to 2012, and they predicted that most of the radioactive cesium that was deposited on the tree crowns would reach the forest bed within the first five years.

Dissolved radioactive cesium is absorbed by microbes, algae, plants, and various other creatures in a forest ecosystem. In a biological community, the radioactive cesium captured by algae, plants, and other primary producers is most likely passed along a food web to a wide range of creatures. Ultimately, it is likely to move up the trophic levels to fish, birds, and mammals. Many past studies on the migration of radioactive substances through food webs have attempted to determine whether biological accumulation takes place ${ }^{8,9)}$.

To deal with forest contamination in the affected areas, it was considered essential to clarify in detail how radioactive cesium deposited in forests is redistributed by migration within the ecosystem and how much of the radioactive cesium is discharged from the system in the initial years. Accordingly, the author and his colleagues conducted a survey in a forest located in northern Fukushima with the following aims: 1) to determine the redistribution mechanism for radioactive cesium in the forest; 2) to assess the amount of radioactive cesium that flows down streams in the hydrological process; and 3) to monitor radioactive cesium migration among creatures in the food web of the biological community. This paper reports the survey results using data obtained by the end of FY2014 to consider necessary surveys and measures for the future. It may be noted that most of the findings have already been published in the references ${ }^{10-12)}$.

\section{Survey Method}

A field survey was conducted at the gully head of the Kami-Oguni River, which runs through the Kami-Oguni district of Ryozenmachi, Date City, in northern Fukushima. According to aircraft observations conducted in June and July of 2013, the air dose rate in the surrounding area ranged from 1.0 to $1.9 \mu \mathrm{Sv} \mathrm{h}{ }^{-1}$ and the expected total amount of ${ }^{137} \mathrm{Cs}$ precipitation was between 100 and $300 \mathrm{kBq} \mathrm{m}^{-213)}$. The main parts of the survey site are covered by a mixed secondary forest made up of Japanese red pine (Pinus densiflora) and deciduous broadleaf trees, such as jolcham oak (Quercus serrata) and Japanese elm (Zelkova serrata). An approximately 50-year-old artificial forest of Japanese cedar (Cryptomeria japonica) extends along the valley.

To track the flux from the radioactive cesium that migrates along with water in these forests, a hydrological observation was conducted to measure the radioactive cesium concentration at various stages from the precipitation to the runoff (e.g., precipitation, passage through crowns, and spillover into streams). Two square plots were assigned to the mixed forest of deciduous broadleaf trees and Japanese red pine as the main part of the forest system. Another plot was assigned to the artificial forest of Japanese cedar. In each of these plots, the litterfall 
(i.e., fallen leaves and branches in a forest) was sampled, and measurements were taken to determine the amount and concentration of radioactive cesium in the throughfall and stemflow.

In addition, land and aquatic creatures were sampled along the stream to determine the extent to which radioactive cesium is transmitted within the biological community. The sampled creatures were identified before the concentration of radioactive cesium in their tissues was measured.

Moreover, standing trees in the main forest were cut down and sampled in November of both 2012 and 2013 to estimate the amount of radioactive cesium buildup above the ground. The samples were divided into live leaves, branches, and trunks (bark, sapwood, and heartwood) to measure the radioactive cesium concentration ${ }^{10,11)}$.

\section{Results and Discussion}

\section{1. ${ }^{137}$ Cs Concentration in Plants}

Live leaves on evergreen Japanese cedar can last for about three years. The leaves that foliate in the current year are called "current leaves," while other leaves that foliated earlier are called "older leaves." Presumably, a certain proportion of the leaves were still attached in the years that followed the deposition of radioactive cesium on them in March 2011. In 2012, the ${ }^{137} \mathrm{Cs}$ concentration in live leaves exceeded $10,000 \mathrm{~Bq} \mathrm{~kg}^{-1}$ for both current leaves and older leaves. The concentration measured in 2013 had dropped to $3,500 \mathrm{~Bq} \mathrm{~kg}^{-1}$ in older leaves and $2,700 \mathrm{~Bq} \mathrm{~kg}^{-1}$ in current leaves (Figure 1). The similar concentration levels observed between leaves that foliated in 2012 and leaves that remained from the previous year suggest that the deposited radioactive cesium was translocated from the crown or other parts of the trees to newly formed leaves. This means that radioactive cesium on the surface of leaves, branches, and trunks can seep into the tree body and that it can be carried via nutrient translocation inside the tree body. The decline in the ${ }^{137} \mathrm{Cs}$ concentration that was observed with older leaves in 2013 can probably be explained by them being replaced with new leaves that have a relatively low concentration and rainfall washing away some of the radioactive cesium.

As a deciduous tree, jolcham oak foliates in early summer and defoliates in late fall, which means that live leaves on the crown are replaced every year. The ${ }^{137} \mathrm{Cs}$ concentration in live leaves was around 1,000 $\mathrm{Bq} \mathrm{kg}^{-1}$ in both 2012 and 2013. In March 2011, when radioactive cesium first fell on the forest, live leaves had not foliated yet. The ${ }^{137} \mathrm{Cs}$ in these samples seems to have seeped into the tree body from the surface of the trunks and branches before further translocation. Meanwhile, some of the ${ }^{137} \mathrm{Cs}$ that was deposited on fallen leaves and the like on the forest floor was absorbed through roots before being transferred to new leaves.

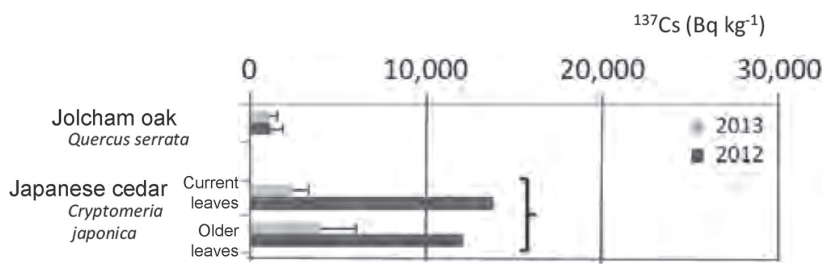

Figure $1{ }^{137} \mathrm{Cs}$ concentration in live leaves on jolcham oak and Japanese cedar

The samples were taken by cutting down standing trees in November of both 2012 and 2013. The concentration was measured separately for older leaves and current leaves on Japanese cedar (Ohte et al., $2015^{11)}$ ). 


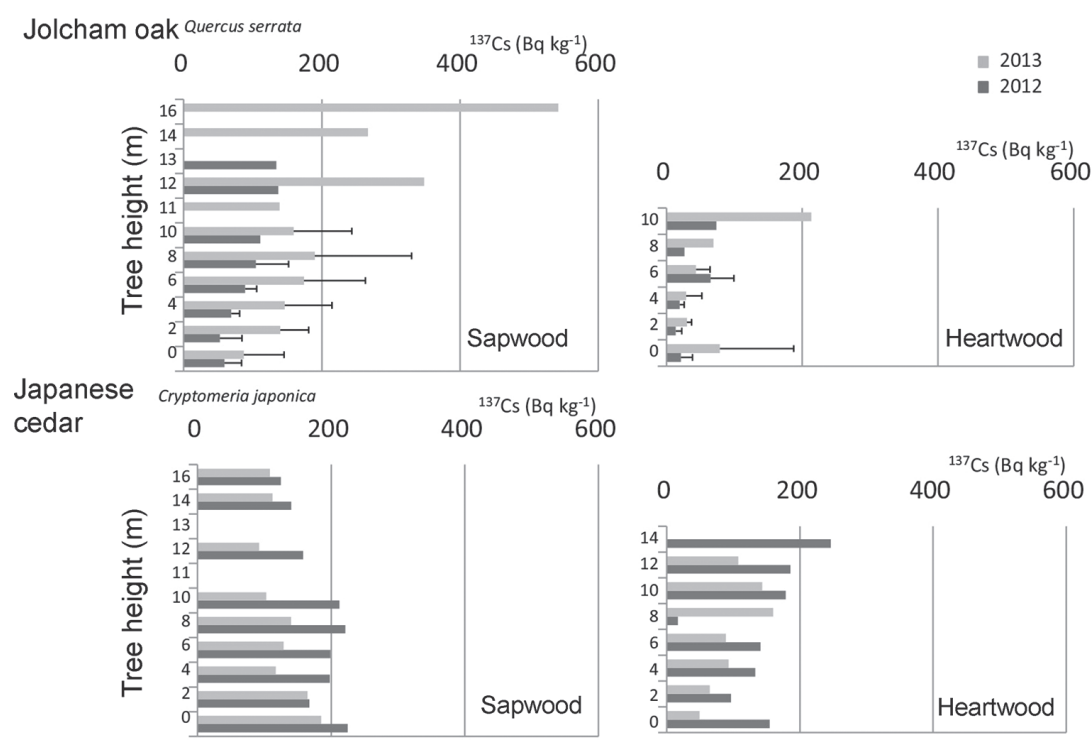

Figure $2{ }^{137} \mathrm{Cs}$ concentration in the sapwood and heartwood of Japanese cedar and jolcham oak The samples were taken by cutting down standing trees in November of both 2012 and 2013 (Ohte et al., $2015^{11)}$ ).

The ${ }^{137} \mathrm{Cs}$ concentration exceeded $10,000 \mathrm{~Bq} \mathrm{~kg}^{-1}$ in most bark samples from jolcham oak during the same period in $2012^{11)}$.

The marginal difference in concentration between the sapwood and the heartwood of Japanese cedar as compared to jolcham oak in both 2012 and 2013 (Figure 2) indicates a much faster translocation of radioactive cesium in a tree trunk of Japanese cedar.

The above findings demonstrate the active movement of radioactive cesium via the nutrient translocation mechanism of trees. Especially, the discovery that a high concentration of radioactive cesium in bark migrates to sapwood and then translocates to leaves is important. The next task would be to conduct a quantitative measurement of the ${ }^{137} \mathrm{Cs}$ absorption through roots under a forest floor covered in heavily contaminated leaves.

\section{Migration of Radioactive Cesium from Tree Crowns to the Forest Floor}

Among the three plots, the greatest migration of ${ }^{137} \mathrm{Cs}$ from tree crowns to the forest floor via litterfall was observed in the artificial cedar forest (Table 1) ${ }^{14}$. As explained in the previous section, this is probably due to the larger amount of radioactive cesium that was deposited on evergreen tree crowns. Even when the throughflow and stemflow were taken into consideration in addition to migration via litterfall, the amount of migration was found to be greatest in the artificial forest of evergreen cedar.

The migration from the tree crowns to the forest floor supplies ${ }^{137} \mathrm{Cs}$ to microbes in the litter and humus layers as well as to the plants that extend their roots there. However, the availability of ${ }^{137} \mathrm{Cs}$ for microbes and plants is believed to be quite different between migration via litterfall and migration via throughfall and stemflow.

In addition to confirming the amount absorbed by trees through their roots as mentioned earlier, detailed surveys need to be conducted to determine the standing stock of radioactive cesium in the upper-litter and humus layers that is readily absorbable by plants and microbes as well as other factors such as seasonal changes in the standing stock of radioactive cesium. 
Table 1 Annual average ${ }^{137} \mathrm{Cs}$ concentration and annual ${ }^{137} \mathrm{Cs}$ flux for throughfall, stemflow, and litterfall

\begin{tabular}{|c|c|c|c|c|c|c|}
\hline & \multicolumn{3}{|c|}{$\begin{array}{c}\text { Annual average }{ }^{137} \mathrm{Cs} \text { concentration } \\
\left(\mathrm{Bq} \mathrm{L} \mathrm{L}^{-1} \text { : Throughfall and stemflow; }\right. \\
\qquad \mathrm{Bq} \mathrm{kg}{ }^{-1} \text { : Litterfall) }\end{array}$} & \multicolumn{3}{|c|}{$\begin{array}{c}{ }^{137} \mathrm{Cs} \text { flux } \\
\left(\mathrm{Bq} \mathrm{\textrm {m } ^ { - 2 }} \text { year }{ }^{-1}\right)\end{array}$} \\
\hline & DP1 & DP2 & $\mathrm{CP}$ & DP1 & DP2 & $\mathrm{CP}$ \\
\hline Throughfall & 3.10 & 3.01 & 5.54 & 3,254 & 1,694 & 3,388 \\
\hline Stemflow & 4.01 & 0.97 & 2.16 & 458 & 101 & 69 \\
\hline Litterfall & 8,068 & 7,464 & 17,887 & 2,904 & 2,125 & 7,518 \\
\hline
\end{tabular}

Footnote: DP1: Mixed forest of deciduous broadleaf trees and Japanese red pine trees 1; DP2: Mixed forest of deciduous broadleaf trees and Japanese red pine trees 2; CP: Artificial forest of Japanese cedar. (Original data source: Endo et al., 2015 ${ }^{14)}$ )
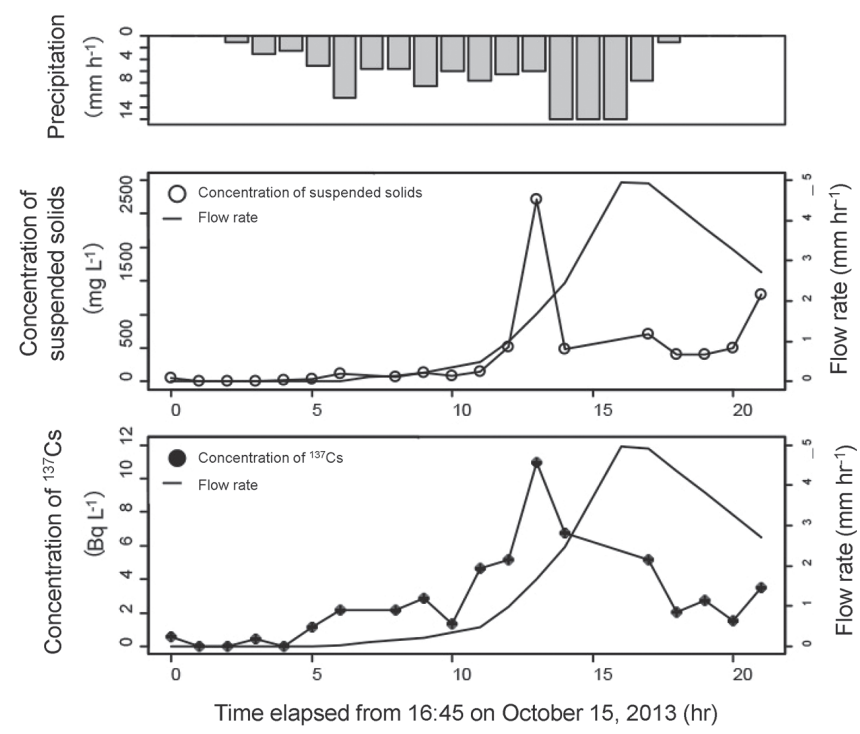

Figure 3 Precipitation, concentration of suspended solids, concentration of ${ }^{137} \mathrm{Cs}$, and river flow over time during a flooding event on October 15, 2013 (Iseda, 2015 ${ }^{15)}$ )

\section{Radioactive Cesium Runoff into Streams}

Figure 3 presents changes in the concentrations of suspended solids and ${ }^{137} \mathrm{Cs}$ over time during their rain-induced runoff into a swollen stream in October 2013 (Iseda, 2015) ${ }^{15}$. These changes are almost synchronized, which indicates that suspended solids served as important carriers for ${ }^{137} \mathrm{Cs}$ runoff.

The annual ${ }^{137} \mathrm{Cs}$ runoff from the catchment area was estimated by taking into consideration the changes in ${ }^{137} \mathrm{Cs}$ concentration associated with changes in the stream's flow rate. The estimated amount for the period from August 31, 2012, to August 30, 2013, was $330 \mathrm{~Bq} \mathrm{~m}{ }^{-2}$ year $^{-15}$. However, it should be noted that just one major flood caused by heavy rain in mid-October 2013 caused a ${ }^{137} \mathrm{Cs}$ runoff of $227 \mathrm{~Bq} \mathrm{~m}^{-2}$ in a matter of a few days. Given this, it is quite important to observe flooding to track the ${ }^{137} \mathrm{Cs}$ runoff from the catchment area accurately.

As mentioned earlier, the estimated ${ }^{137} \mathrm{Cs}$ deposition in this area is 100 to $300 \mathrm{kBq} \mathrm{m}$, which is three orders of magnitude greater than the estimated runoff in a period of one year. 
Given ${ }^{137} \mathrm{Cs}$ 's half-life of roughly 30.1 years, the amount of radioactive cesium that is discharged from a forest ecosystem into rivers through hydrological processes is apparently much less than the amount that disappears due to radioactive decay within the system.

\section{Migration of Radioactive Cesium in Food Webs}

Figure 4 presents the ${ }^{137} \mathrm{Cs}$ concentration among samples of land and aquatic creatures broken down by functional group. The concentration for fallen leaves, fungi, scavengers, and predators was significantly higher than that for the live leaves on plants and plant-eating creatures.

Fallen leaves and their fragments that have built up on the ground surface retain the largest amount of ${ }^{137} \mathrm{Cs}$, which migrated noticeably among land creatures from these sources. Fallen leaves and their fragments and benthic algae, which serve as basic food for aquatic creatures, had ${ }^{137} \mathrm{Cs}$ concentration levels that were somewhere between the concentration levels for live leaves and those for fallen leaves on the ground. The ${ }^{137} \mathrm{Cs}$ concentrations among creatures in higher trophic levels could be explained by a combination of the concentration levels explained earlier ${ }^{16)}$.

The nitrogen stable isotope ratio increases in the tissues of creatures in higher trophic levels, so it can be regarded as a relative indicator of tropic levels. The measured ratio and the ${ }^{137} \mathrm{Cs}$ concentration among creature samples exhibited a slightly negative correlation. In other words, the ${ }^{137} \mathrm{Cs}$ concentration was lower among creatures in higher trophic levels, which indicates that no biological accumulation of ${ }^{137} \mathrm{Cs}$ took place in the biological community studied in this survey ${ }^{16)}$.

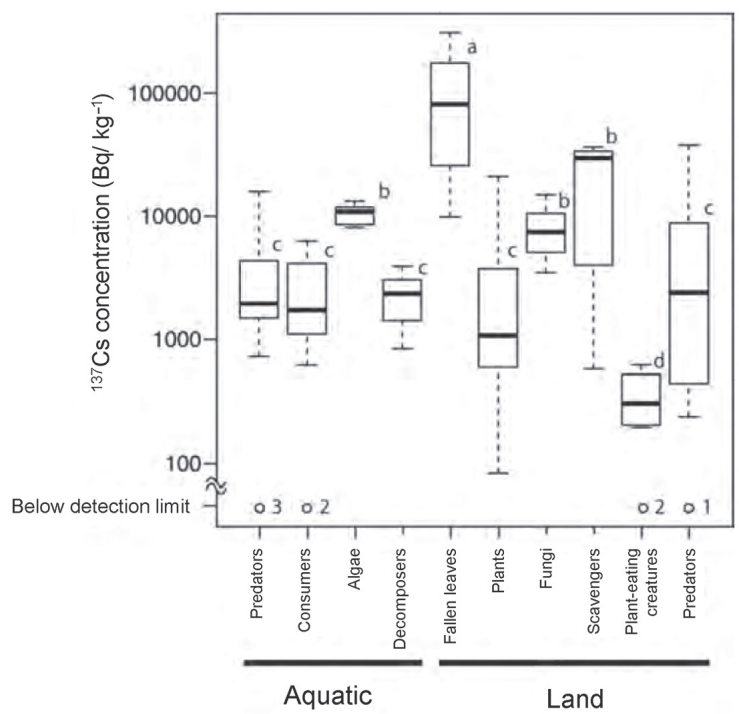

Figure $4{ }^{137} \mathrm{Cs}$ concentration by functional group

The alphabetic denotation assigned to each plot represents its functional group according to the statistical grouping. The same letter represents the same functional group. There were samples below detection limit for predators and consumers in aquatic, plant-eating creatures and predators in land. The number of those samples is indicated after circle (Murakami et al. $2014^{16)}$ ). 


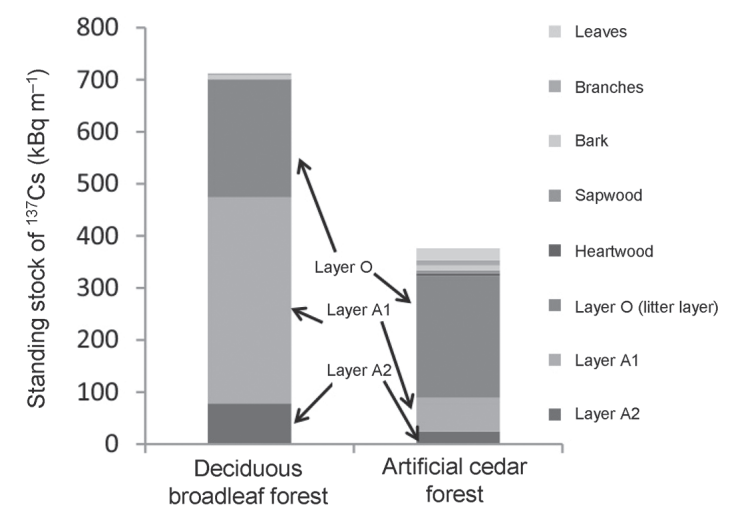

Figure 5 Distribution of the standing stock of ${ }^{137} \mathrm{Cs}$ among parts of the plots covered respectively by a deciduous broadleaf forest and an artificial cedar forest as of September 2014 (yet to be published) Layer O represents a sedimentary layer of fallen leaves and branches. Layers A1 and A2 are the most superficial mineral soil layers with a notable comingling of organic matter.

\section{Conclusions}

Figure 5 presents the standing stock of ${ }^{137} \mathrm{Cs}$ in each part of the plots covered respectively by a deciduous broadleaf forest and an artificial cedar forest as of September 2014.

These different types of forests commonly retain the greatest amount of ${ }^{137} \mathrm{Cs}$ in their litter layers and topsoil. The buildup inside plants is expected to be relatively small. Nonetheless, the most crucial finding of the monitoring that has been conducted so far is the fact that radioactive cesium continues to migrate actively without any stable distribution with a specific spatial alignment. The internal circulation in the ecosystem was particularly visible along nutrient cycle pathways between plants and the soil. The ${ }^{137} \mathrm{Cs}$ migration diminished year by year in the evergreen artificial forest of Japanese cedar, with the concentration in the trees' new needle leaves at the level of a few thousand $\mathrm{Bq} \mathrm{kg}^{-1}$. In the future equilibrium, the amount of absorption into the tree body is expected to reach a similar level to the amount of migration to the forest floor.

Meanwhile, a certain portion of the ${ }^{137} \mathrm{Cs}$ is believed to seep down into the mineral soil layer to be retained by clay minerals. However, internal circulation between plants and the litter and humus layers is expected to last for a long time. The availability of radioactive cesium for creatures is reduced by its adsorption and retention by clay minerals. However, it is reasonable to assume that radioactive cesium remains available for creatures as long as the internal circulation is maintained between plants and the litter and humus layers. The internal circulation mechanism and the circulated amount of radioactive cesium must be observed carefully and continuously. In addition to the monitoring that is to be continued in the medium to long term, detailed studies on the processes that take place in litter layers and on the ground surface remain important.

\section{Acknowledgments}

This study was conducted with financial assistance from the Grants-in-Aid for Scientific Research Program (24248027 and 16H04934), the River Development Program run by the River Foundation (2014 and 2015), and the Grant Program for Environmental Research Projects run by the Sumitomo Foundation (FY2015 and 2016). It also owes a tremendous debt 
to the generous support provided by Mr. Chonosuke Watanabe from the Kami-Oguni district of Ryozenmachi, Date City.

\section{References}

1) MEXT and MAFF (2012): Report Based on a Survey Conducted on the Distribution of Radioactive Materials Released as a Result of an Accident at TEPCO's Fukushima Daiichi Nuclear Power Station [in Japanese], Survey Conducted to Provide a Rapid Response to Important Policy Challenges and Policymaking by the CSTI, Financed by the FY2011 Strategic Fund for the Promotion of Science and Technology: Building a Foundation to Address the Environmental Impact of Radioactive Substances [in Japanese].

2) S. Hashimoto, T. Matsuura, K. Nanko, I. Linkov, G. Shaw, and S. Kaneko S (2013): Predicted Spatio-temporal Dynamics of Radiocesium Deposited onto Forests Following the Fukushima Nuclear Accident, Sci Rep 3: 2564.

3) N. Kruyts and B. Delvaux (2002): Soil Organic Horizons as a Major Source for Radiocesium Biorecycling in Forest Ecosystems, J Environ Radioact 58: 175-190.

4) Y. Wakiyama, Y. Onda, S. Mizugaki, H. Asai, and S. Hiramatsu (2010): Soil Erosion Rates on Forested Mountain Hillslopes Estimated Using ${ }^{137} \mathrm{Cs}$ and ${ }^{210} \mathrm{Pbex}$, Geoderma 159: 39-52.

5) H. Kato, Y. Onda, and T. Gomi (2012): Interception of the Fukushima Reactor Accident-Derived ${ }^{137} \mathrm{Cs},{ }^{134} \mathrm{Cs}$ and ${ }^{131} \mathrm{I}$ by Coniferous Forest Canopies, Geophys Res Lett 39: L20403.

6) W. Schimmack, H. Förster, K. Bunzl, and K. Kreutzer K (1993): Deposition of Radiocesium to the Soil by Stemflow, Throughfall and Leaf-Fall from Beech Trees, Radiat Environ Biophys 32: 137-150.

7) K. Hisadome, Y. Onda, A. Kawamori, and H. Kato (2013): Migration of Radiocaesium with Litterfall in Hardwood-Japanese Red Pine Mixed Forest and Sugi Plantation [in Japanese], Collection of papers from the Japanese Forest Society 95: 267-274.

8) D. J. Rowan and J. B. Rasmussen (1994): Bioaccumulation of Radiocesium by Fish: The Influence of Physicochemical Factors and Trophic Structure, Can J Fish and Aquat Sci 51: 2388-2410.

9) W. X. Wang, C. Ke, K. N. Yu, and P. K. S. Lam (2000): Modeling Radiocesium Bioaccumulation in a Marine Food Chain, Mar Ecol Prog Ser 208: 41-50.

10) N. Ohte, M. Murakami, K. Iseda, K. Tanoi, and N. Ishii (2013): Diffusion and Transportation Dynamics of ${ }^{137} \mathrm{Cs}$ Deposited on the Forested Area in Fukushima after the Nuclear Power Plant Accident in March 2011, In: T. Nakanishi and K. Tanoi (eds), Agricultural Implications of the Fukushima Nuclear Accident. Springer, New York, pp 177-186.

11) N. Ohte, M. Murakami, I. Endo, M. Ohashi, K. Iseda, T. Suzuki, T. Oda, N. Hotta, K. Tanoi, N. Kobayashi, and N. Ishii (2016): Ecosystem Monitoring of Radiocesium Redistribution Dynamics in a Forested Catchment in Fukushima after the Nuclear Power Plant Accident in March 2011, In: T. Nakanishi and K. Tanoi (eds), Agricultural Implications of the Fukushima Nuclear Accident: First Three Years. Springer, New York, pp 177-186.

12) N. Ohte, M. Murakami, I. Endo, and N. Hotta (2016): Dynamics of Radioactive Cesium Deposited in a Forest Ecosystem as a result of a Nuclear Accident [in Japanese], pp 18-27, T. Ichinose and M. Kamada (eds), Forest Environment 2016. Forest Culture Association, Tokyo.

13) MEXT (2015): Distribution Maps of Radiation Doses, Etc. [in Japanese]. http://ramap.jmc.or.jp/map/ (accessed August 2, 2016)

14) I. Endo, N. Ohte, K. Iseda, K. Tanoi, A. Hirose, N. I. Kobayashi, M. Murakami, N. Tokuchi, and M. Ohashi (2015): Estimation of Radioactive 137-Cesium Transportation by Litterfall, Stemflow and Throughfall in the Forests of Fukushima, J Environ Radioact 149: 175-188.

15) K. Iseda (2015): Study on Changing Dynamics of ${ }^{137}$ Cs Runoff Accompanied by Suspended Sediment in a Forest in Northern Fukushima [in Japanese], Master's thesis at Graduate School of Agricultural and Life Sciences, The University of Tokyo.

16) M. Murakami, N. Ohte, T. Suzuki, N. Ishii, Y. Igarashi, and K. Tanoi (2014): Biological Proliferation of Cesium-137 through the Detrital Food Chain in a Forest Ecosystem in Japan, Sci Rep 4: 3599. 